\title{
LA REPÚBlicA DOMINICANA 2007: \\ BUSCANDO LA INSTITUCIONALIDAD
}

\author{
The Dominican Republic 2007: In Search of Institutionality
}

\section{CHRISTOPHER MITCHELL}

New York University

\begin{abstract}
RESUMEN
Se examinan aspectos económicos y sociales de los eventos dominicanos de 2007, enfatizando la continuación de un manejo neoliberal de los asuntos macroeconómicos. Los resultados han incluido un incremento en la estabilidad política, junto con un descontento social apreciable. Los preparativos para los comicios presidenciales del año 2008 reciben atención, y se sugiere que el sistema político puede evolucionarse hacia un sistema bipartidista. Se discuten varias políticas públicas específicas, entre ellas la seguridad ciudadana, la educación, el manejo de desastres naturales (especialmente tormentas tropicales), la corrupción, y la construcción de un Metro en Santo Domingo. Se analiza el anhelo bastante difundido de una institucionalidad política mayor, junto con los obstáculos que impiden la realización de esa aspiración.
\end{abstract}

Palabras clave: Partidos políticos, elecciones, economía, instituciones, neoliberalismo.

\begin{abstract}
Economic and social aspects of Dominican affairs in 2007 are examined, stressing continued neo-liberal, macro-economic management. The result has been political stability along with considerable social discontent have resulted. Political parties' preparations for the 2008 presidential elections are outlined, and it is noted that the Dominican polity may be evolving from a three-party to a two-party system. Public policy issues are analyzed, including: citizens' security, education, natural disaster (storm) management, corruption, and the building of a metro for Santo Domingo. A commonly-perceived need for greater political institutionality is described, together with obstacles to its achievement.
\end{abstract}

Key words: Political parties, elections, economy, institutions, neo-liberalism.

\section{LA COYUNTURA ECONÓMICA}

Durante 2007 la economía dominicana continuó un patrón económico establecido a fines del año 2004: crecimiento notable del PIB (8\%), superávit presupuestario del gobierno central (US\$ 500 millones), tipo de cambio manejado y estable (alrededor de 34 pesos dominicanos por dólar US), déficit en el comercio internacional, y un persistente nivel elevado del desempleo (16-18\%). Las políticas públicas para apoyar este modelo fueron instituidas por el actual régimen del presidente Leonel Fernández Reyna (Partido de la Liberación Dominicana - PLD), elegido en mayo de 2004 para un mandato que terminará en agosto de 2008. El objetivo principal de esta política -creada con la ayuda del Fondo Monetario 
Internacional- ha sido restablecer la estabilidad y la expansión económica, luego de una crisis muy aguda de inflación monetaria y de contracción productiva, experimentada en 2003-2004. La administración de ese período, encabezado por el presidente Hipólito Mejía Domínguez (Partido de la Revolución Dominicana - PRD) aumentó el circulante hasta tal punto que el peso bajó del nivel de 20 por dólar US (enero de 2003) a 45 por dólar (julio de 2004). En el manejo instaurado por el equipo económico del PLD, una combinación de alzas tributarias, administración cuidadosa de los tipos de cambio y de interés, atracción de inversiones extranjeras, y otras medidas han fortalecido la confianza psicológica y las reservas de divisas en el Banco Central (US\$ 1,6 mil millones en diciembre de 2007) (Banco Central 2007b).

Otro fenómeno económico importante en 2007 fue el impacto del libre comercio internacional sobre las zonas francas industriales dominicanas. Los continuados efectos de la terminación del Acuerdo Multi-Fibra en 2005, y del inicio del Acuerdo de Libre Comercio DR-CAFTA, redujeron sustancialmente las exportaciones de las industrias livianas dominicanas. Durante los cinco primeros meses del año, el valor de las exportaciones dominicanas de confecciones textiles bajó en un $26 \%$ en comparación con el mismo período en 2005, y en el mismo lapso el valor total de las exportaciones industriales disminuyó en un 9,6\% (Banco Central 2007a). Los propietarios en ese sector industrial notaron una pérdida de más de 50.000 empleos. A fines del año, el gobierno creó un programa de ayuda financiera al sector, con pagos iniciales de más de US\$ 6 millones.

Los problemas de las zonas francas probablemente contribuyeron a contrastes entre el ritmo de crecimiento de diversos sectores económicos durante 2007. Mientras que los bancos y el sector de comunicaciones expandieron en un $28 \%$ y un $18 \%$ respectivamente, las manufacturas y la agricultura sólo crecieron en un $2 \%$, mientras que el volumen de la construcción disminuyó durante el año. Los sectores actualmente en auge generalmente no generan muchos empleos. ("Crecimiento RD..." 2007).

\section{LA COYUNTURA SOCIAL}

La sociedad dominicana fue afectada en 2007 por factores internos y externos, y el mayor impacto externo, proveniente de Haití, influyó la estructura misma del pueblo dominicano. En lo interno, la nación sufrió repetidos desastres naturales, y también produjo protestas contra los bajos ingresos y la relativa escasez de trabajo. Dos tormentas tropicales -“Noel" en octubre y "Olga" en diciembre- causaron inundaciones y desprendimientos de tierras, con un saldo de 56 muertos y más de 58.000 desplazados en el primer caso, y 33 víctimas y 61.000 sin techo, en el segundo. Ambos ciclones ocasionaron críticas a la capacidad del Estado para alertar a la población ante la llegada de un huracán, igual que a su competencia para los trabajos de rescate y de reconstrucción. "Noel", que se desarrolló muy rápidamente, sorprendió al encargado Centro de Operaciones de Emergencia (COE) en la tarde de un día domingo, y la advertencia "roja" llegó tarde para muchos moradores de zonas afectadas. Días después, una fuente anónima del COE informó que el Centro sólo contó con menos del $10 \%$ de las radios necesarias para funcionar efectivamente, y que muchos 
de éstos habían sido comprados por los voluntarios mismos (Marte 2007). En el caso de "Olga", varios observadores preguntaron si las autoridades habían escogido el momento más apto para abrir las puertas de la Presa Tavera (cerca de Santiago de los Caballeros, segunda ciudad del país). El presidente Fernández nombró una comisión oficial para fijar responsabilidades en el caso.

A principios de julio y otra vez en octubre, una coalición de organizaciones populares, el Foro Social Alternativo (FSA), lanzó paros cívicos, presionando por aumentos de sueldos, subsidios de transporte para los estudiantes, control de los precios de alimentos básicos, y un rompimiento con el FMI. "Se sabe que este es un gobierno prepotente, sordo y que no se conecta con las necesidades de la gente", declaró Fidel Santana, uno de los dirigentes del FSA, en octubre (Valdez Zambrano 2007). Apoyados por la mayoría de los dueños de autobuses que dominan el transporte urbano, estas huelgas limitaron la circulación en las principales ciudades, y crearon un impacto positivo en la opinión pública, mientras que presentaron un reto efectivo, si bien transitorio, al régimen del PLD.

En cuanto a factores externos, 2007 fue un año en que la sociedad dominicana tuvo que confrontar los problemas -y las percepciones dentro y fuera del país-asociados con la presencia de entre 650.000 y un millón de haitianos, en una población total de 9,2 millones. Los tipos de trabajo ofrecidos a los inmigrantes indocumentados del país vecino son variados, pero existe un factor casi uniforme. En sectores rurales o urbanos, informales o relativamente bien organizados (cortado de caña, construcciones, etc.), el elemento constante es el estatus subordinado, muchas veces precario, de los haitianos, que vienen casi obligados por la extrema pobreza de su país. Durante 2007, un coro crítico se expresó contra las violaciones de los derechos humanos de los haitianos en territorio dominicano -un conjunto de voces que incluyó la Comisión de los Derechos Humanos de la República Dominicana, el Departamento de Estado de los Estados Unidos, sacerdotes católicos que habían sido expulsados del país por su militancia a favor de los inmigrantes, artistas extranjeros y políticos franceses, entre otros (USA Department of State 2007). La ONG Amnesty International publicó un informe detallado y muy crítico, bajo el título significativo de Una Vida en Tránsito (Amnesty International 2007). El lema refirió a la tesis legal del Estado dominicano, para justificar su política de negar la ciudadanía a hijos de haitianos indocumentados, nacidos en territorio dominicano. La doctrina oficial dominicana, aprobada por una decisión (2005) de la Suprema Corte de Justicia, es que los padres estén "en tránsito", excepción constitucional al sistema de jus solis utilizado por la jurisprudencia dominicana. Esta política goza actualmente del apoyo de la opinión pública; sólo el 43,4\% de los dominicanos encuestados apoyarían la concesión de la ciudadanía a los hijos de inmigrantes haitianos nacidos en la República Dominicana (Morgan y Espinal 2006: 188-189). Políticos y oficiales dominicanos rechazaron las múltiples censuras con indignación, citando la notable diversidad fenotípica de la población dominicana, y los beneficios ocasionales suministrados por el Estado dominicano a residentes haitianos. Por ejemplo, el régimen dominicano provee ciertos servicios obstétricos para mujeres haitianas embarazadas, que alegadamente viajan a la República Dominicana específicamente para dar a luz allí. 


\section{COYUNTURA SUBREGIONAL E INTERNACIONAL}

La política exterior dominicana mantuvo en 2007 un balance cuidadoso en sus relaciones con dos potencias influyentes en el Caribe: Estados Unidos y Venezuela. El tratado de libre comercio DR-CAFTA, estrechando los lazos entre la República Dominicana y Estados Unidos, entró en vigor para el país oficialmente el 1 de marzo de 2007. El presidente Fernández elogió al nuevo pacto como una gran oportunidad para diversificar los mercados internacionales para productos dominicanos, y para atraer nuevas inversiones y fomentar el crecimiento económico (Presidencia de la República 2007c; Servicio DR1, 22 marzo 2007). Orientándose simultáneamente hacia el sur, la diplomacia dominicana formalizó su participación en el arreglo PetroCaribe, a través del cual Venezuela vende hasta 50.000 barriles diarios de petróleo crudo, con $50 \%$ del costo financiado en términos blandos por hasta 25 años. Leonel Fernández visitó Caracas en agosto, y en diciembre participó en una cumbre de PetroCaribe en Cienfuegos, Cuba. En las últimas semanas de 2007, además, el gobierno dominicano anunció planes para comprar a la corporación multinacional Shell el 50\%, que todavía no controló, de la única refinería nacional de petróleo. El propósito principal era expandir y modificar la planta para procesar el tipo de crudo entregado actualmente por Venezuela.

\section{COYUNTURA POLÍTICA}

Los políticos dominicanos pasaron gran parte de 2007 preparándose para las elecciones presidenciales que se celebrarán el 16 de mayo de 2008. El sistema político todavía está centrado fundamentalmente en el Ejecutivo, y el voto popular ha constituido, sin cambio desde 1966, la ruta hacia el Palacio Nacional. La Constitución política del Estado, enmendada más recientemente en 2002, permite al presidente Fernández (PLD) una segunda (y última) postulación, mientras que el partido principal opositor, el PRD, no puede presentar al ex presidente Mejía, quien gastó su segunda candidatura en un esfuerzo perdedor en 2004. Leonel Fernández también ocupó la presidencia entre 1996 y 2000, mandato que no entra en el cálculo constitucional contemporáneo. La tercera fuerza electoral, el Partido Reformista Social Cristiano (PRSC, o el "Reformismo"), no ha ocupado la presidencia desde 1996, y ha perdido mucho apoyo popular desde la muerte de su fundador y caudillo, ex presidente Joaquín Balaguer (1906-2002).

El factor más importante en la evolución de la campaña -por lo menos hasta su inicio formal en las primeras semanas de 2008- probablemente ha sido el rechazo popular del mal gobierno del PRD en el período de Hipólito Mejía (2000-2004). Es cierto que Mejía tomó unas medidas positivas, tales como la elevación de la Secretaría del Medio Ambiente al rango del gabinete, y el incremento del subsidio central para los gobiernos municipales. Sin embargo, su legado principal yace en la corrupción gigantesca, que contribuyó a la quiebra del banco comercial más grande del país, llamado Baninter, en 2003. Los propietarios saquearon a la institución, sin intervención por los inspectores oficiales. El Estado rápidamente reembolsó a los depositantes, inyectando el equivalente de US\$1,5 
mil millones (sin respaldo) en la economía, la cual reaccionó con la inflación galopante ya descrita. Con este trasfondo, empeorado por la actitud despreciativa y jocunda de Mejía ante la crisis nacional que había provocado, Leonel Fernández apareció como un estadista serio y responsable, y el PLD ganó los comicios de 2004 con el 57\%, contra 34\% para Mejía, y menos de 9\% para Eduardo Estrella del PRSC. Encuestados en 2006, 88\% de los respondientes dominicanos consideraron la corrupción como un problema grave. Sin embargo, en cuatro de entre seis tipos específicos de abusos en el servicio público, los ciudadanos percibieron una mejora desde 2004. Puede haber motivos entre los votantes, entonces, para continuar un gobierno responsable por una tendencia que se percibe como positiva (Morgan y Espinal 2006: 71-73).

La República Dominicana cuenta con un conjunto de partidos políticos de masas, anclados en un nivel notable de identificación partidaria entre sus seguidores. Desde 1982, el sistema ha incluido los tres competidores principales ya mencionados, cada uno con representación en el Congreso y con la demostrada capacidad para conquistar la presidencia. Esfuerzos recientes para invadir y dividir este "espacio político", con la formación de nuevos partidos, han fracasado; el partido principal más joven (el PLD) cumplió 34 años en 2007. El poder de los líderes nacionales, dentro de sus partidos, resulta en parte de su control sobre la designación de los candidatos electorales, y de los funcionarios públicos (cuando ocupan la silla presidencial). Las listas de candidatos para cargos legislativos y municipales son abiertas (desde 2002), pero tradicionalmente eran cerradas, fortaleciendo el poder de las autoridades partidarias. Los diputados y concejales se eligen según el sistema d'Hont de representación proporcional, mientras que los senadores (uno por cada provincia) y los síndicos (alcaldes) son escogidos por pluralidad. Los partidos practican un clientelismo penetrante, en formas muy diversas, desde los contratos sin licitación pública, a las "botellas" -puestos sin responsabilidad alguna, salvo la oportunidad de cobrar cada dos semanas.

El Estado financia a los partidos políticos cada año, en sumas que fluctúan según el calendario electoral. En años de elecciones generales (presidenciales o parlamentarias / municipales) los partidos reciben un fondo equivalente al medio por ciento de los ingresos nacionales. En años no electorales, los partidos comparten una suma que equivale a un cuarto por ciento de la misma base financiera. Este financiamiento ahora significa un flujo global de US\$ 50 millones en años electorales. El ochenta por ciento se distribuye en partes iguales entre los partidos grandes, que hayan obtenido más del cinco por ciento de los votos en los últimos comicios; el restante veinte por ciento ayuda a los partidos minoritarios, con una leve ventaja para los que recibieron una mayor cantidad de votos. En la actualidad, esta fórmula favorece notablemente al PRSC (Junta Central Electoral 2008).

Hasta la década de los noventa, los partidos dominicanos presentaron perfiles ideológicos relativamente claros, los cuales habían sido establecidos durante la década después de la muerte (1961) del dictador Rafael Trujillo y Molina. El PRSC era un partido de centro-derecha, dominado por Balaguer, ex ayudante del tirano. El PRD representó el centro-izquierda, y fue afiliado al Internacional Socialista. El PLD, producto de un 
fraccionamiento del PRD en 1973, seguía una línea izquierdista, abogando por "una dictadura con apoyo popular". Con los numerosos cambios de los últimos veinte años -el creciente poder del neoliberalismo internacional, la crisis de la deuda soberana, las muertes de los fundadores de los tres partidos- los programas partidarios ahora casi coinciden, y sería difícil distinguirlos con claridad. Sin embargo, el analista muy sagaz Bernardo Vega (ex embajador en Washington, ex gobernador del Banco Central) no tiene toda la razón cuando observa "la única diferencia entre [líderes del PRD] y [dirigentes del PLD] es que unos van a misa de cinco y los otros a misa de ocho" (Vega 2007). Aunque el PLD ahora aspira (con un grado de éxito impresionante) a ocupar el espacio político de centro-derecha, conserva por lo menos una parte de su estructura disciplinada original, típica de un partido de izquierda. El PRD, en cambio, padece de muchas divisiones personalistas, y numerosos rencores, causados especialmente por las maniobras del ex presidente Mejía.

En un contraste con la práctica en el pasado, los tres partidos principales escogieron sus candidatos presidenciales para 2008 con mucha anticipación, con elecciones primarias en escala nacional en 2007. El PRD fue el primero, designando a Miguel Vargas Maldonado, un hombre de negocios en el sector de construcción, y ex Secretario de Obras Públicas en el gobierno de Mejía; Vargas derrotó a Milagros Ortiz Bosch, ex vicepresidenta del país, con $80 \%$ de los votos, el 28 de enero. Los participantes en las primarias del PLD optaron por Leonel Fernández en mayo, dándole más de $70 \%$ de los votos contra su rival, Danilo Medina, ex asesor económico y político de Fernández, y ex candidato presidencial del partido (contra Mejía) en el año 2000. El PRSC condujo el único proceso electoral controvertido de 2007, nombrando a Amable Aristy Castro, con un anunciado 55\% de los votos, el 10 de junio. El principal contrincante de Aristy, Eduardo Estrella, denunció el resultado como fraudulento, y más tarde dejó el partido para montar una campaña presidencial con un partidito menor. Aristy Castro es el barón de una provincia en el este del país (La Altagracia), y desde 1998 ha sido el Secretario Ejecutivo de la Liga Municipal Dominicana (LMD). Hasta mediados de 2007, la Liga sirvió de intermediario financiero entre el Estado central y los 147 municipios dominicanos, recibiendo un 5\% de los subsidios por sus "servicios". La dirección de la LMD fue tan atractiva para Aristy que en dos ocasiones (en 2000 y en 2004) renunció a una senaduría para continuar como jefe de la Liga.

La Constitución contempla dos vueltas electorales para escoger el Ejecutivo, exigiendo $50 \%$, más uno, para la victoria en primera vuelta. El PLD, según las encuestas publicadas a fin de año, tiene la mayor posibilidad de evitar una segunda ronda. Una encuesta de diciembre, coauspiciada por Gallup y el matutino Hoy, ubica al PLD con 47\% de las intenciones de voto, al PRD con 31\%, y al PRSC con 10\%. La intención probable del presidente Fernández es tratar de eliminar al candidato reformista en la primera vuelta, y luego confiar en una campaña activa para agregar por lo menos la mitad de los votantes reformistas a su causa, suficiente para triunfar en la segunda vuelta. La estrategia del PLD, por más de diez años, ha tratado de reclutar líderes y bases del PRSC (especialmente) y del PRD, pero en capacidad personal y no organizativa. A lo largo, dada la disminución de la votación presidencial reformista desde 2000, el PLD tiene perspectivas para convertirse 
en un polo principal de un sistema de dos partidos competidores nacionales, junto con el PRD. Esa posibilidad puede ser incrementada por el perfil anacrónico de Aristy como un candidato abiertamente clientelista, en el estilo más crudo de la época de Balaguer. Aristy hace campaña repartiendo, desde su "yipeta" Hummer, billetes con valores de entre US\$ 1 y US\$ 15, gallinas congeladas, y "canastas para embarazadas" en los barrios más pobres de Santo Domingo y otras ciudades (Ogando 2007).

Dos otros temas significativos forman parte del mosaico político dominicano de 2007: las finanzas públicas, e informes y alegatos sobre la corrupción. Luego de muchos años de penuria, el Estado dominicano se ha vuelto muy próspero, con un presupuesto equivalente a casi US\$ 10 mil millones -28\% del PIB nacional. El gobierno terminó el año 2007 con un superávit estimado en US\$ 500 millones. La afluencia del Estado se debe al crecimiento económico, a las alzas tributarias, y a una mayor eficiencia en la recaudación de los impuestos. Este fenómeno permite a los políticos que controlan el Estado reducir la influencia de algunos grupos de presión, como los empresarios y los terratenientes. En las palabras de un dirigente de una ONG cívica en Santo Domingo, "el poder del Estado ya excede el de los intereses privados; el presidente es como un emperador pequeño -y no tan pequeño" (entrevista con el autor, No. 304, 2007; Aizpun 2007). También, como puede ser obvio, la solvencia del gobierno sólo agrega motivos para una lucha política más intensiva, para controlar una entidad tan rentable.

La ONG Transparency International, en su Índice de Percepciones de Corrupción 2007, ubica a la República Dominicana en la posición número 99 (de entre 179 países); 20 de los 32 Estados del Hemisferio Occidental alcanzaron posiciones más favorables en el índice (Transparency International 2007). Episodios muy difundidos durante el año sugirieron las causas de esta lamentable clasificación. En el otoño, algunos periodistas alegaron que el Ejecutivo había contratado secretamente un préstamo de US\$ 130 millones, en cooperación con una corporación norteamericana de mala reputación, la Sun Land Corporation. La presidencia insistió que la operación era legítima y legal, pero luego de unas semanas el arreglo fue suspendido. En octubre, dos ex funcionarios de Baninter fueron declarados culpables en el caso, y condenados a diez años de cárcel y a restituir casi US\$ 2 mil millones (un pago muy poco probable, en la realidad). Ningún político ni empleado del Estado ha sido acusado, aunque la estafa del banco habría sido difícil sin el apoyo tácito de la burocracia oficial; los condenados han apelado sus sentencias. Muchos alegatos de corrupción también han involucrado el tema del medio ambiente. A fines de agosto, Max Puig, ex Secretario del Medio Ambiente (2004-2007), renunció a otro cargo oficial con una carta dirigida a Leonel Fernández, incluyendo la frase: “Usted, mejor que nadie, conoce todo cuanto tuvimos que hacer para enfrentar corruptos de los más diversos litorales políticos que pretendían, y todavía pretenden, lamentablemente, despojar a la nación de sus espacios protegidos" ("Max Puig pide castigo", 2007). Se puede debatir si este texto fue un elogio o una crítica al presidente. 


\section{POLÍTICAS PÚBLICAS, Y PLANES PARA CAMBIOS CONSTITUCIONALES}

La política pública más fundamental del gobierno de Leonel Fernández es el modelo económico ya descrito. El restablecimiento del crédito nacional, límites en el endeudamiento soberano, y el mantenimiento de un superávit en el presupuesto público se han combinado con un crecimiento notable, pero desequilibrado. Los bancos multinacionales y las instituciones financieras internacionales han elogiado la estrategia del PLD, pero dentro del país el desempleo, el alto costo de la vida y problemas con los servicios del Estado han provocado algunas protestas. Sectores exportadores -de manufacturas, materias primas, y servicios tales como el turismo- se han quejado del tipo de cambio que, según ellos, ha sido sobrevaluado. Para el muy disciplinado equipo económico del gobierno, sin embargo, la combinación de medidas ha evitado una serie de males significativos: la recesión, la falta de acceso a fuentes de financiamiento externo, y la inflación más allá de un ritmo aceptable de aproximadamente $5 \%$ anualmente.

Otro motivo por los elementos neoliberales del manejo económico es la necesidad de reunir recursos para confrontar un legado muy persistente de la crisis causado por la quiebra de Baninter. Para reducir la cantidad de dinero en circulación, y por consiguiente limitar el impacto inflacionario del reembolso de los depositantes, el Banco Central a partir de 2003 vendió bonos que llegaron en 2007 al valor de US\$ 5,47 mil millones. Pagar intereses sobre esta suma actualmente vale un 2,7\% del PIB, un costo denominado el "déficit cuasi fiscal" (Clave Digital 2007: 20). Una ley fue aprobada en 2007 para eliminar gradualmente este insólito déficit del Banco Central, pero el proceso necesitará diez años para alcanzar esa meta. Además, el gobierno falló en su intento de mejorar el servicio de electricidad -un problema frustrante que ha atormentado al país por más de quince años- y de reducir los subsidios pagados al sector por el Estado. Las compañías distribuidoras sólo cobran el $58 \%$ de las facturas, y el gobierno eroga casi US\$1,5 mil millones en subvenciones cada año (Servicio DR1, 10 de diciembre de 2007).

La iniciativa gubernamental principal en 2007 fue la continuada construcción de la primera línea del Metro de la capital, Santo Domingo. Iniciado a fines de 2005, el proyecto creará una línea de 14 kilómetros de extensión, uniendo la sección norte de la ciudad con el malecón frente al Mar Caribe. A pesar de las dudas expresadas por muchos expertos en el transporte urbano, el presidente Fernández ha invertido capital político -y una suma estimada entre US\$ 700 millones y US\$1,6 mil millones para terminar esta primera faseen la enorme obra (Lacey 2007; de León 2007). El encargado principal de este esfuerzo ha sido Diandino Peña (ex Secretario de Obras Públicas en el primer mandato de Fernández), con el cargo de Director de la Oficina Para el Reordenamiento del Transporte (OPRET). Varias calles y avenidas del sector afectado han sido convertidas, por lo menos temporalmente, en trincheras formidables, y en muchos períodos el tráfico de camiones y excavadoras continúa día y noche. El proyecto -financiado en parte con créditos brasileños de exportación- implica una serie de grandes contratos con empresas de construcción, perforación, excavación, demolición, etc. (Bautista 2005). El presidente considera al Metro como un paso básico para modernizar a la ciudad capital, siguiendo el modelo de Nueva 
York, donde él pasó varios años en su juventud. Las voces críticas suelen ser mordaces; el columnista Pedro Herrera Maluf escribió en mayo que el proyecto estaba "destripando la ciudad sin piedad" (Herrera 2007).

En cuanto a los servicios públicos, el gobierno dominicano intentó, con resultados mixtos, responder a presiones o necesidades urgentes en tres áreas: la seguridad ciudadana, la educación, y el manejo de desastres naturales. El sentido de inseguridad sigue como una preocupación de la opinión pública. Mientras que en 1994 el 42\% de los participantes en una encuesta nacional se sintieron menos seguros en comparación con su situación cinco años antes, en 2006 79\% se sintieron menos confiados en su seguridad personal (Morgan y Espinal 2006: 86). En 2007 el Estado montó varios esfuerzos para combatir el crimen. Un programa llamado "Barrio Seguro" tiene el fin de estrechar lazos entre la Policía Nacional y entidades comunitarias, especialmente en los barrios más humildes de Santo Domingo y de Santiago. (Lamentablemente, la compra de más de cincuenta motocicletas grandes, de marca Harley-Davidson, para patrullar estos barrios fue un fracaso. Los vehículos, con un costo de US\$17,000 por unidad, resultaron demasiado grandes y pesados para navegar en las calles y senderos de los vecindarios.) Limitar las horas de venta de alcohol, especialmente en altas horas de la noche, dio ciertos resultados, y en septiembre el secretario del Interior y Policía, Franklin Almeyda, declaró que el crimen había bajado en un 20\% durante los primeros siete meses del año. Sin embargo, persistían muchas razones para creer que grandes mejoras todavía eran posibles. El propio Secretario Almeyda reveló en octubre, en las palabras de un cronista, "que 15 mil miembros de la Policía Nacional no trabajan para la institución, sino para funcionarios públicos y el sector privado". "Actualmente", dijo el secretario, "sólo diez mil policías están patrullando las calles de la capital y otros puntos del país" (González 2007). Además, fiscales trabajando en Santo Domingo observaron que el público resistía informar sobre crímenes que habían sufrido, por temor a la policía misma.

La educación no motivó protestas populares durante 2007, pero fue una preocupación prominente de grupos influyentes de la élite nacional, sobre todo entre los empresarios. La República Dominicana devota sólo 2,5\% de su PIB al sector educativo, y durante 2007 un estudio prestigioso internacional confirmó notables debilidades en el rendimiento de la instrucción pública en el país. El Programa de Promoción de la Reforma Educativa en América Latina (PREAL), apoyado por el BID, la USAID, el Banco Mundial y otras entidades, informó que la República Dominicana había ampliado la participación en la educación primaria a casi $100 \%$ del grupo elegible. Sin embargo, la cobertura neta del nivel secundario era de apenas 50\%, el gasto público por alumno de primaria era casi el menor de la región, y los exámenes uniformes demostraron deficiencias en el aprendizaje de los alumnos dominicanos. En las palabras de PREAL:

En los resultados de las pruebas realizadas en 2001, que son las únicas que poseen un análisis detallado de qué saben o no los alumnos, los estudiantes de octavo grado mostraron un dominio bajo en matemáticas y lengua española. Los promedios de los que terminaban el bachillerato en ese mismo año también fueron muy bajos: de 53 puntos, valor inferior a la meta de 70 puntos. (PREAL 2007)

En enero el Ejecutivo dominicano patrocinó un Foro Presidencial por la Excelencia de la Educación Dominicana. En su discurso al inaugurar el foro, Leonel Fernández resaltó la 
importancia del sector para el futuro nacional ("sólo la Educación salva a la República Dominicana"), pero insistió en las ventajas de mejorar la eficiencia y eficacia del sistema instructivo, en vez de "reducir el tema al ámbito [presupuestario] exclusivo" (Presidencia 2007a). En septiembre, una coalición de grupos empresariales y desarrollistas enfatizó la posibilidad de un impacto negativo de la baja calidad educativa sobre la competitividad económica del país, y exhortó al gobierno asignar el 5\% del PIB a la educación, tal como exige la ley educativa. Muchos comentaristas lamentaron los gastos multimillonarios para el Metro, en un momento de grandes necesidades para servicios básicos como la educación.

Hemos notado ya la serie de obstáculos encontrados por el Estado, frente a desastres naturales como huracanes o inundaciones. Estas dificultades resultan de causas que incluyen la hipertrofia de la nómina de empleados del Estado, enfatizando la cantidad y no la calificación de los funcionarios; el bajo nivel de disciplina y de organización en la Policía Nacional, instrumento potencialmente útil para confrontar las emergencias; y la escasez de fondos para comprar (y para proteger) provisiones que sólo serán utilizados en un futuro indefinido. La inequidad en la distribución del ingreso también juega un rol en esta problemática: los diluvios frecuentemente ahogan a comunidades enteras de pobres, que han construido sus casuchas en el lecho de un río, por falta de un terreno más seguro. La posibilidad de aparecer como incompetente o insensible, frente a los sufrimientos de miles de víctimas, representa un peligro reconocido para cualquier administración, y Leonel Fernández y su equipo son muy activos después de cada tormenta. Mandan comida y frazadas, organizan refugios en edificios públicos, apelan para ayuda de entidades nacionales y extranjeras, y anuncian proyectos para reemplazar algunas de las casas destruidas. Sin embargo, a veces es difícil cumplir con las promesas. En uno de sus recorridos recientes de campaña, unos ciudadanos pobres pidieron a Amable Aristy del PRSC la terminación de unas casas, iniciadas por el Estado en 1998 tras el Huracán “Georges” de ese año.

El medio ambiente seguía como el foco de intensa atención política durante 2007. La protección y explotación responsable de los recursos naturales dominicanos constituye un tema muy relevante, no sólo por su significado inherente, sino también porque el país se ve obligado a actualizar su estrategia para el desarrollo. Si las zonas francas están en descenso, y el turismo "todo incluido" en playas de la costa Este también pierde dinamismo, las regiones montañosas y costeras todavía no explotadas atraen el interés de inversores y de medioambientistas, con puntos de vista muchas veces opuestos. Este debate, en que los defensores del medio ambiente optan por el "eco-turismo", salvaguardando los recursos y buscando mayores ganancias per cápita entre los viajeros, se tradujo en una pugna en 2007 entre las secretarías de turismo, por un lado, y del medio ambiente, por el otro. El secretario del medio ambiente, Max Puig, alegó en mayo que legisladores de distintos partidos planearon modificar una ley de áreas protegidas para conceder tierras del patrimonio nacional a entidades particulares, para construcciones, tala de árboles, y otros fines. (Mejía 2007). El año anterior, Puig y sus aliados habían frustrado, por lo menos temporalmente, un intento para construir grandes hoteles en una playa prístina del suroeste, conocida como la Bahía de las Águilas. Miembros del Congreso reaccionaron enérgicamente a los alegatos de Puig, y fueron secundados por el secretario de Turismo, Félix Jiménez, un admirador del modelo 
tradicional de hoteles grandes, y un participante en grupos inversores del sector. En agosto, Puig perdió su cargo de secretario, y renunció poco después a un puesto meramente formal, con la carta que hemos examinado ya. Otra batalla aparentemente perdida por Puig fue su esfuerzo para prohibir la extracción de arena y de gravilla de los lechos fluviales, para la construcción. En los últimos meses de 2007, esa práctica (que contribuye a la erosión de tierras) fue autorizada de nuevo; el régimen citó la urgencia de encontrar estos materiales rápidamente, para facilitar la reconstrucción después de los ciclones de otoño.

Dos cambios institucionales fueron propuestos durante 2007; uno fue aprobado, y el otro fue pospuesto por razones políticas. En julio, una nueva ley de organización municipal fue aprobada por el Congreso. La nueva legislación concedió más autonomía a los municipios, y eliminó el rol de la Liga Municipal como distribuidor de los subsidios del gobierno central a las autoridades municipales (Zabala 2007). De un golpe, la ley privó al candidato presidencial del PRSC, y Secretario Ejecutivo de la Liga, de una fuente principal de fondos para su campaña. Otra nueva ley instituyó el Presupuesto Participativo como una obligación para cada municipio, en el planeamiento de una proporción de sus egresos (CONARE 2007). Anteriormente, ese sistema de programación venía ganando apoyo entre los municipios, pero había sido voluntario.

Un esfuerzo para reformar la Constitución Política del Estado, lanzado con mucha publicidad por el presidente Fernández en 2006, no procedió en 2007. El mandatario había descrito la reforma como un concomitante necesario de reformas en las leyes electorales, municipales y de organización judicial. El plan había ganado cierto apoyo de los otros partidos, y de las organizaciones cívicas. La administración del PLD escogió una manera de reformar la Constitución que convierte al Congreso en una Asamblea Nacional, requiriendo una mayoría de 67\% para aprobar cambios en la Carta Magna. Un proceso de "consulta nacional" (utilizando el Internet, entre otras modalidades) produjo un borrador, que incorporó ciertas innovaciones legislativas recientes (por ejemplo, la posición del Defensor del Pueblo) (Comisión Ejecutiva para el Proceso de Reforma Constitucional 2006). El texto preliminar también garantizó el derecho de amparo, e instituyó el referendum y la iniciativa ciudadana para presentar leyes. (Presidencia 2007b). Se discutía mucho si el Ejecutivo trataría de reinstituir la reelección indefinida, tal como fue permitido entre 1966 y 1996, pero este interrogante no pudo contestarse. La delegación del PLD en el Congreso habría tenido que mantener su unidad, y también necesitaría la ayuda de legisladores de otros partidos. La división dentro del partido gobernante obligó la postergación del proceso de reforma. Los seguidores de Danilo Medina, entre los legisladores fieles al PLD, indicaron que no favorecieron el proyecto de reforma, eliminando el margen de apoyo necesario.

\section{PODER EJECUTIVO}

Hay 17 secretarios de Estado con portafolio, nombrados y sólo removibles por el presidente; actualmente, 3 de éstos (19\%) son mujeres. La Constitución permite la interpelación legislativa de miembros del gabinete, y ese inciso se utilizó una vez en 2007 (para interrogar al secretario Puig en el Senado, acerca de sus acusaciones de corrupción entre 
los legisladores). La gran mayoría de los ministros son militantes del PLD, con la excepción del canciller, Carlos Morales Troncoso. Morales era miembro del PRSC, y sirvió como vicepresidente del país, 1986-94. Leonel Fernández no nombra nuevos secretarios de Estado con frecuencia, y en 2007 sólo había tres cambios, anunciados en el tercer aniversario de la actual administración, el 16 de agosto. En Obras Públicas, Víctor Díaz Rua reemplazó a Freddy Pérez; en Industria y Comercio, Melanio Paredes sucedió a Francisco Javier García, y en Medio Ambiente, Max Puig salió, y Omar Ramírez asumió el cargo. En la misma ocasión, la administración continuaba su esfuerzo para reclutar a ex partidarios de los partidos competidores, preparándose para las elecciones presidenciales de 2008. Elías Wessín Chávez, jefe del aliado minipartido Quisqueyano Democrático (PQD), fue nombrado Jefe de Bienes Nacionales. Hasta julio de 2007, José Francisco Peña Guaba, hijo del fallecido héroe del PRD José Francisco Peña Gómez, dirigía el Instituto Nacional de Estabilización de Precios (Nova 2007); del PRSC, Leonardo Matos Berrido, operador político en que confiaba Balaguer, es director ejecutivo del Banco Nacional de la Vivienda.

El gabinete funciona con un círculo íntimo y otro círculo amplio; el gabinete en pleno sólo se reúne ocasionalmente. El equipo íntimo generalmente incluye (además del presidente Fernández) a Juan Temístocles Montás, el Secretario Técnico de la Presidencia y el ayudante más prominente del mandatario, y a Vicente Bengoa, secretario de Hacienda.

El presidente Fernández es el político dominicano más hábil de su generación. Su estilo personal es muy cordial, pero correcto. Políticamente, combina una astucia táctica aguda con una visión estratégica que le permite planear con años de anticipación. Relativamente joven (nació en 1953), cuenta con la capacidad de comunicar bien por los medios electrónicos, algo todavía relativamente raro entre los líderes dominicanos, con su tradición de declamar ante manifestaciones de 25.000 y más personas. En este mandato, igual que en su anterior administración, Fernández ha creado un círculo de asesores tecnócratas muy capaces y muy fieles. Él cultiva el perfil de un tecnócrata también, aprendiendo los detalles de las políticas públicas en un grado notable. Sin embargo, el presidente también puede tomar el rol de un político implacable, necesario para cualquier primer mandatario. Prefiere discursos tradicionales al intercambio informal con los periodistas, y suele no insertarse en polémicas hasta que percibe las posibles ganancias y pérdidas involucradas. Aunque valora mucho la disciplina entre miembros de su gobierno, a veces tolera las discrepancias entre ellos, para mantener sus lazos con varias corrientes de opinión; su paciencia con el debate sobre el desarrollo de las playas es un buen ejemplo de esta característica. Demostró su enfoque estratégico, en 2007, con su apoyo a la nueva ley orgánica de los municipios: con una sola acción, complació a muchos funcionarios locales en todo el país, y puso en peligro la base financiera de un nivel político importante. Entiende mejor que la mayoría de sus colegas la importancia de la arena internacional para el éxito del país, y el de sus gobernantes. Viaja mucho al exterior, un trabajo para representar a la nación que le trae ventajas en la política interior. Después de su primer mandato, creó una ONG, la Fundación Global Democracia y Desarrollo (FUNGLODE), que ya cuenta con un edificio impresionante y funcional en Santo Domingo, y que mantiene un programa de conferencias, seminarios, y proyectos de estudio. La Fundación probablemente servirá como su base para continuar en la arena pública luego de dejar la presidencia. 


\section{PODER LEGISLATIVO}

Los tres partidos principales son representados así en el Congreso:

Tabla 1: Resultados de las elecciones parlamentarias 2006

\begin{tabular}{llcc}
\hline & PLD & PRD & PRSC \\
\hline Senado & & & \\
Porcentaje votos* & $46,4 \%$ & $31 \%$ & $11 \%$ \\
Número escaños & 22 & 6 & 4 \\
Porcentaje escaños & $69 \%$ & $19 \%$ & $12 \%$ \\
\hline Cámara de Diputados & & & \\
\hline Porcentaje votos* & $46,4 \%$ & $31 \%$ & $11 \%$ \\
Número escaños & 95 & 60 & 23 \\
Porcentaje escaños & $53 \%$ & $34 \%$ & $13 \%$ \\
\hline
\end{tabular}

Fuente: Junta Central Electoral 2008a.

* El restante $11,6 \%$ de los votos favorecieron a 17 partidos minoritarios.

Las elecciones legislativas, para mandatos de cuatro años en ambas cámaras, son celebradas a dos años de los comicios presidenciales; el actual Congreso fue elegido en 2006, y se renovará en 2010. (Las elecciones municipales son concurrentes con las parlamentarias.) Como es evidente, el PLD goza de una mayoría confortable en ambas cámaras, y el presidente Fernández encuentra pocos problemas en asegurar la aprobación de proyectos favorecidos. La disciplina partidaria, en situaciones normales, es fuerte, aunque ha habido casos en los últimos diez años de legisladores que han desertado, a cambio de favores del Ejecutivo. Las elecciones de medio término ofrecen a un Ejecutivo popular la posibilidad de fortalecer su autoridad dos años después de su propia elección; eso ayudó a Mejía en 2002, y a Fernández en 2006. Un partido sin control del Ejecutivo también puede beneficiarse de comicios parlamentarios, si el presidente en ejercicio es vulnerable; el PRD aprovechó las elecciones de 1998 para sentar las bases para su victoria presidencial dos años más tarde. En principio, un mandatario recién elegido podría verse frustrado por una mayoría legislativa opuesta, "heredada" de un voto de medio término. Sin embargo, tal efecto no apareció para Fernández en 2004, puesto que la derrota del PRD en las elecciones presidenciales de ese año fue tan rotunda; la mayoría parlamentaria del PRD, entre 2004 y 2006, se portó de una manera muy mansa con el nuevo presidente PLDista. No hay datos sobre la eficiencia del ramo legislativo; la rapidez con que se considera proyectos de ley depende generalmente del grado de interés del Ejecutivo en la propuesta. Hay proyectos - por ejemplo para el reordenamiento de las tierras urbanas- que han permanecido "bajo consideración" por años enteros, mientras que el presupuesto anual se considera y se aprueba cada año en menos de tres semanas, generalmente sin cambios sustanciales. 


\section{RELACIÓN ENTRE LOS PODERES DEL ESTADO}

El Ejecutivo sigue como el eje del gobierno dominicano. El Poder Judicial y el Poder Legislativo han ganado un grado más amplio de independencia en los últimos diez años, pero la iniciativa política y el poder financiero quedan mayormente en manos del presidente. Hace diez años, se creó el Consejo Nacional de la Magistratura, para nombrar jueces de la Suprema Corte. El Consejo incluye, además del presidente de la República, los presidentes de las dos cámaras, y un miembro de cada cámara, de filiación política opuesta. Esta reforma protege a la Corte de los peores vaivenes políticos, pero hay pocas discrepancias entre el Ejecutivo y los fallos importantes judiciales. En cuanto al Congreso, especialmente cuando hay mayorías oficialistas en ambas cámaras (como es el caso ahora), el Parlamento no es una arena central de decisiones básicas. (Hay mucho debate allí, por cierto, y mucha retórica, pero el impacto sobre las políticas públicas suele ser superficial.)

\section{RELACIÓN ENTRE LOS DISTINTOS NIVELES DE GOBIERNO}

A pesar de la existencia formal de 32 provincias, en realidad hay sólo dos niveles de gobierno: el central, y el municipal. Los municipios no poseen muchas competencias, de acuerdo con las leyes municipales: administran los parques, el servicio de bomberos, recolección de basura, mercados públicos, cementerios, y ornato municipal. Los gobiernos locales carecen de fuentes apreciables de ingresos, en la forma de impuestos; dependen fundamentalmente de subsidios del gobierno central. Sin embargo, los síndicos y concejales son elegidos cada cuatro años (juntos con los legisladores), y la lucha política municipal, ocurriendo a medio término presidencial, constituye una arena donde los partidos nacionales pueden demostrar fuerza (o debilidad) ante los ojos del público nacional. Desde 1997, los fondos compartidos del erario nacional con los municipios han crecido considerablemente, tras una serie de nuevas leyes y decretos, respondiendo a presiones políticas del nivel municipal. La ley más reciente (de 2003) requiere al gobierno central mandar 10\% de sus ingresos ordinarios a los municipios; esta suma teóricamente sería de US\$ 1 mil millones. En la realidad, aproximadamente 5,5\% está entregado a los gobiernos locales -más de US\$ 500 millones (entrevista con el autor No. 301, 2007). Todavía no está claro cómo las relaciones entre el Estado central y los municipios hayan de cambiar, bajo la nueva ley orgánica del gobierno municipal (Mitchell 2007).

\section{EVALUACIÓN GENERAL SOBRE EL FUNCIONAMIENTO Y CALIDAD DE LA DEMOCRACIA}

Existe un consenso impresionante entre los observadores y participantes más perspicaces de la política dominicana, sobre cuál es la necesidad más urgente en el futuro inmediato: incrementar la institucionalidad política. El sistema gubernamental tiene una fuerte herencia "neopatrimonial" (Hartlyn 1998), pero tras muchos sacrificios se ha eliminado (en 1978) la amenaza de nuevos golpes militares, tanto como (entre 1994 y 1996) los peores 
efectos del fraude electoral. Estos avances necesitan ser consolidados, con la creación de instituciones capaces de resistir e influenciar el poder de un Ejecutivo todavía muy poderoso y -como hemos notado- creciendo en poder financiero. Abundan los ejemplos de tendencias políticas lesivas, que florecen ante la ausencia de una cuota mayor de instituciones jurídicas, legislativas, y cívicas, que sean fuertes y activas. Los bienes nacionales -sea el crédito público, o los parques nacionales- caen a menudo en manos privadas; el Estado puede emprender enormes proyectos, como el Metro, sin consulta pública o parlamentaria digno del nombre; necesidades urgentes como mejorar la educación no reciben la atención que merecen, puesto que los intereses que sirven son muy generales, y no poseen la debida influencia en los pasillos gubernamentales. Muchos funcionarios de la administración actual reconocen esta dinámica, y actúan para limitarla -pero el trabajo es lento, y encuentra muchos obstáculos.

Observadores bien informados fuera del país coinciden con este criterio. Expertos encuestados por la Konrad Adenauer Stiftung estimaron la calidad de la democracia en la República Dominicana en 2007 entre las peores de América Latina, sólo excediendo a la clasificación de Venezuela y de Nicaragua, entre 18 casos. Leves mejoras desde 2006, en la protección de los derechos civiles, en la corrupción percibida, y en el PIB per cápita, fueron sobrepasados por reducciones en categorías que incluían rendición de cuentas ("accountability"), estabilidad política, equidad de géneros, desempleo urbano, desigualdad económica, y gastos para la educación (Konrad Adenauer Stiftung y Polilat.com 2007). El cambio negativo dominicano, en comparación con las estimaciones para 2006, fue el más grande entre los países hemisféricos.

Por bien o por mal, la evidencia disponible no indica que el pueblo dominicano actualmente arda con una pasión para reformar la política y para fortalecer las instituciones. El Informe Latinobarómetro de noviembre de 2007, con base en encuestas de la opinión pública en la República Dominicana (como en 17 otros países), ubica al público dominicano en la tercera posición en satisfacción con la democracia (con 49\% del muestreo), en tercera en confianza en los partidos políticos (30\%), y en segunda en confianza de que todos los ciudadanos tienen iguales oportunidades de acceso a la justicia (33\%). En cuanto a servicios específicos, $66 \%$ de los participantes dominicanos expresaron satisfacción con el sistema de salud (segundo entre 18), y 71\% se declararon contentos con la educación (tercero entre 18) (Corporación Latinobarómetro 2007).

Vale la pena recordar, en este contexto, que el sistema democrático dominicano sí proporcionó al pueblo -en la crisis nacional de 2003-2004- una manera pacífica para reemplazar a una administración sumamente irresponsable. Puede ser que "el hombre de la calle" dominicano esté expresando, en sus respuestas a las preguntas de Latinobarómetro, una apreciación de esa utilidad notable de las elecciones y del Estado de derecho en el país. La otra cara de la moneda, importante tanto para los partidarios del fortalecimiento institucional como para los políticos prácticos, es que los dominicanos no están tan satisfechos con el gobierno actual del PLD. En la misma encuesta 2007 de Latinobarómetro, sólo el 46\% de los dominicanos expresaron aprobación de "la gestión del gobierno", y sólo el 41\% manifestaron confianza en el presidente Fernández. La lucha política electoral, en otras palabras, continúa. Probablemente el esfuerzo para reformar y fortalecer las instituciones 
dominicanas tendrá que montarse en la arena misma de la competencia política y electoral. Su posible éxito dependerá en parte de la disposición de los combatientes políticos para incorporar avances estructurales entre sus prioridades, en futuras campañas.

\section{REFERENCIAS}

Amnesty International. 2007. Dominican Republic: A life in transit - The plight of Haitian migrants and Dominicans of Haitian descent. [En línea]. <http://www.amnesty.org/en/report/info/AMR27/001/2007>. [Consulta: 04-01-2008].

Aizpun, Inés. 2007. “La Revolución”, Diario Libre (Santo Domingo), 24 de mayo de 2007.

Bautista, Kaelis. 2007. "Cinco empresas nacionales han ganado seis licitaciones, según la Opret", Clave Digital (Santo Domingo), 12 de diciembre de 2005.

Clave Digital (Santo Domingo). 2007. "Evaluación 3 años de gobierno: política económica”, 16 de agosto de 2007.

Corporación Latinobarómetro. 2007. Informe Latinobarómetro 2007: Banco de datos en línea. [En línea]. $<$ http:/ /www.latinobarometro.org >. [Consulta: 28-12-2007].

"Crecimiento RD genera pocos puestos de trabajo", Hoy (Santo Domingo), 12 de diciembre de 2007.

de León, Rafael Osiris. 2007. “El Metro y sus impactos: Tercera parte”. [En línea] <http:/ / 200.88.113.180/ Members/osirisdeleon/metro-de-santo-domingo/el-metro-de-santo-domingo-uasd-14-febrero-2007tercera-parte.ppt/view>. [Consulta: 10-01-2008].

Entrevista con el autor $N^{\circ}$. 301. 2007. Funcionario de una organización intergubernamental, Santo Domingo, 23 de enero de 2007.

Entrevista con el autor N No. 304. 2007. Funcionario de una ONG cívica, Santo Domingo, 30 de enero de 2007.

González, Radhamés. 2007. "Franklin Almeyda dice 15 mil policías trabajan para funcionarios", Hoy (Santo Domingo), 10 de octubre de 2007.

Hartlyn, Jonathan. 1998. The Struggle for Democratic Politics in the Dominican Republic. Chapel Hill, NC: University of North Carolina Press.

Herrera Maluf, Paulo. 2007. “Uno de vaqueros”, 2 de mayo de 2007. [En línea]. <http:/ / www.pciudadana. com/articulos_analisis/art_2007/05022007por_paulo_herrera.htm>. [Consulta: 07-01-2008].

Konrad Adenauer Stiftung y Polilat.com. 2007. "Índice de desarrollo democrático de América Latina". [En línea]. <http:/ /www.idd-lat.org/Edicion2007english.htm>. [Consulta: 11-01-2008].

Lacey, Marc. 2007. "A Subway: Just What's Needed. Or is it?" New York Times, 3 de septiembre de 2007.

Marte, Germán. 2007. "Insisten en que faltan los equipos para alertar", Hoy (Santo Domingo), 6 de noviembre de 2007.

"Max Puig pide castigo para los corruptos y mantiene apoyo a la reelección". 2007. Clave Digital (Santo Domingo), 9 de septiembre de 2007.

Mejía, Odalís. 2007. “Dice legisladores planean reducir áreas protegidas”, Hoy (Santo Domingo), 29 de mayo de 2007.

Mitchell, Christopher. 2007. "The Process of Political Decentralization in the Dominican Republic", trabajo presentado en la $27^{\circ}$ Congreso de LASA, Montreal, Octubre de 2007.

Morgan, Jana, y Rosario Espinal. 2006. The Political Culture of Democracy in Dominican Republic: 2006. Latin American Public Opinion Project (LAPOP), Vanderbilt University. [En línea]. <http://sitemason. vanderbilt.edu/lapop/DOMINICANREPBACK>. [Consulta: 30-01-2008].

Nova, José. 2007. "Peña Guaba confirma su renuncia del Inespre", Listín Diario (Santo Domingo), 12 de julio de 2007.

Ogando, Mayra. 2007. “En medio de caos y desorden Amable reparte dinero”, Diario Libre (Santo Domingo), 11 de octubre de 2007.

Programa de Promoción de la Reforma Educativa en América Latina (PREAL). 2007. Mucho por Hacer: Informe del progreso educativo de Centroamérica y la República Dominicana. [En línea]. <http:/ /www. preal.org/Progreso.asp? Id_Progreso=5>. [Consulta: 28-12-2007]. 
República Dominicana, Banco Central. 2007a. “Exportaciones de Zonas Francas por Grupos de Productos 1995 - Enero/Mayo 2007" [En línea] <http://www.bancentral. gov.do/estadisticas_economicas/ sector_externo/exportaciones_zonas_francas.xls $>$. [Consulta: 10-01-2008].

República Dominicana, Banco Central. 2007b. "Reservas Internacionales del Banco Central" [En línea] $<$ http://www.bancentral.gov.do/estadisticas_economicas/sector_externo/reservas_internacionales. xls>. [Consulta: 10-01-2008].

República Dominicana, Comisión Ejecutiva para el Proceso de Reforma Constitucional. 2006. Consulta popular para la reforma constitucional (preguntas solicitando los comentarios ciudadanos). (Santo Domingo, sin fecha).

República Dominicana, CONARE (Consejo Nacional de Reforma del Estado). 2007. [En línea] <http:// www.reforma.gov.do/Archivos/Documentos/Leyes/Ley\%20170-07.pdf>. [Consulta: 10-01-2008].

República Dominicana, Junta Central Electoral. 2008a. "Elecciones Congresionales 2006". [En línea]. <http://jce.do/stor/Boletines/2006/19/PDF/B19_A_SA.pdf>. [Consulta: 04-02-2008].

República Dominicana, Junta Central Electoral. 2008b. "Ley Electoral No 275-97 y sus modificaciones". [En línea]. http://www.jce.do/web/PARTIDOS/LeyesyReglamentaciones/tabid/126/Default. aspx. [Consulta: 04-02-2008].

República Dominicana, Presidencia. 2007a. "Discurso pronunciado por el presidente Leonel Fernández Reyna en el acto inaugural del Congreso del Foro Presidencial por la Excelencia de la Educación Dominicana, Efectuado el 17 de enero" [En línea] <http://www.presidencia.gob.do/app/pre_ discursos_det.aspx?id=7546\&e=1\%2f17\%2f2007>. [Consulta: 09-01-2008].

República Dominicana, Presidencia. 2007b. “Discurso pronunciado por el presidente Leonel Fernández ante la Asamblea Nacional con motivo del 163 Aniversario de la Independencia Nacional [27 de febrero de 2007]". [En línea]. <http://www.presidencia.gob.do/app/pre_discursos_det. aspx?id=7564\&e=2\%2f27\%2f2007>. [Consulta: $11-01-2008]$.

República Dominicana, Presidencia. 2007c. "Presidente Fernández presenta Plan Nacional de Competitividad Sistémica", 21 de marzo de 2007. [En línea] <http://www.presidencia.gob.do/app/article. aspx?id=7355\&from=search $>$. [Consulta: 07-01-2008].

Servicio "DR1", resumen diario de la prensa dominicana. 2007 [En línea]. <http://www.dr1.com/>. [Consulta: varias fechas].

Transparency Internacional. 2007. "Corruption Perceptions Index 2007" [En línea] <http:/ /www. transparency.org/policy_research/surveys_indices/cpi/2007>. [Consulta: 07-01-2008].

USA, Department of State, Bureau of Democracy, Human Rights, and Labor. 2007. "Country Reports of Human Rights Practices, 2006 -- Dominican Republic" [En línea]. <http://www.state.gov/g/drl/ rls/hrrpt/2006/78889.htm>. [Consulta: 04-01-2008].

Vega, Bernardo. 2007. “Misas de 5:00 y 8:00”, Clave Digital (Santo Domingo), 24 de mayo de 2007.

Zabala, Máximo. 2007. "Diputados aprueban proyecto que quita poderes a la LMD", El Caribe (Santo Domingo), 13 de julio de 2007.

Zambrano, Lidia Valdez. 2007. "Foro Social Alternativo afirma paro es efectivo en primeras 4 horas", Clave Digital, 2 de octubre de 2007.

Christopher Mitchell es Profesor de Ciencia Política en New York University (NYU). Es especialista en el cambio político en los países de América Latina, y en la migración como tema en las relaciones interamericanas. Recibió su B.A. y su Ph.D. en Harvard University. Sus publicaciones incluyen: Changing Perspectives in Latin American Studies (Stanford University Press, 1988), Western Hemisphere Immigration and United States Foreign Policy (Penn State Press, 1992), y ensayos en Canadian Journal of Latin American and Caribbean Studies, y Latin American Research Review. Actualmente sus estudios se enfocan en la descentralización política en la República Dominicana. (E-mail: cm3@nyu.edu) 
